\title{
Recollection
}

\section{Cornell University and modern biology in China}

\author{
Ming Li
}

Beijing Institutes of Life Science, Chinese Academy of Sciences, Beijing 100101, China

The development of modern biology in China can be traced back to the early 1910s, when the first group of young Chinese was sent abroad for higher education. They were mainly supported by the Boxer Indemnity Fund and other American philanthropic funds, such as the Rockefeller Foundation's China Medical Board and the China Foundation. Therefore, most of these young Chinese received their scientific training in certain American universities like the Columbia University and Cornell University.

Chi Ping (秉志) is probably one of the most famous Chinese alumni of Cornell University (Fig. 1). Obtaining his B.S. degree in Cornell in 1913 and his Ph.D. degree in 1918 under the guidance of his advisor Prof. J. G. Needham, Chi Ping returned to China to establish the first biology department of the national university in China, the Department of Biology at the Southeast University, in 1921. He also founded the first biological research institute in China, the Biological Laboratory of the Science Society of China, in 1922 and later the China Zoological Society (founded in 1934). He even co-founded the first non-governmental scientific society of China, the Science Society of China, in 1915 in Ithaca, US, while he was studying at Cornell. Moreover, he was also the co-founder of 'KeXue' ('科学' meaning 'Science' in Chinese), the first Chinese scientific journal.

From the 1910 s to 1930 s Cornell University trained many Chinese students, who turned out to be the backbone of Chinese biology later. These alumni include entomologists Shuwen Zou (邹树文), Chenfu F. Wu (胡经甫) and Chung-Lo Liu (刘崇乐). Chenfu F. Wu published Catalogus Insectiorum Sinensium which recorded a total of 25 orders, 392 families, 4968 genera, 20,069 species of insects and was the most complete publication of Chinese insects of his time. Shisan C. Chen (陈桢), the first director of the Institute of Zoology of the Chinese Academy of Sciences (CAS) and one of the founders of animal genetics in China, also studied at the Department of Agriculture of Cornell University. In addition, zoologist Cheng-Chao Liu (刘承到), who specialized in am-

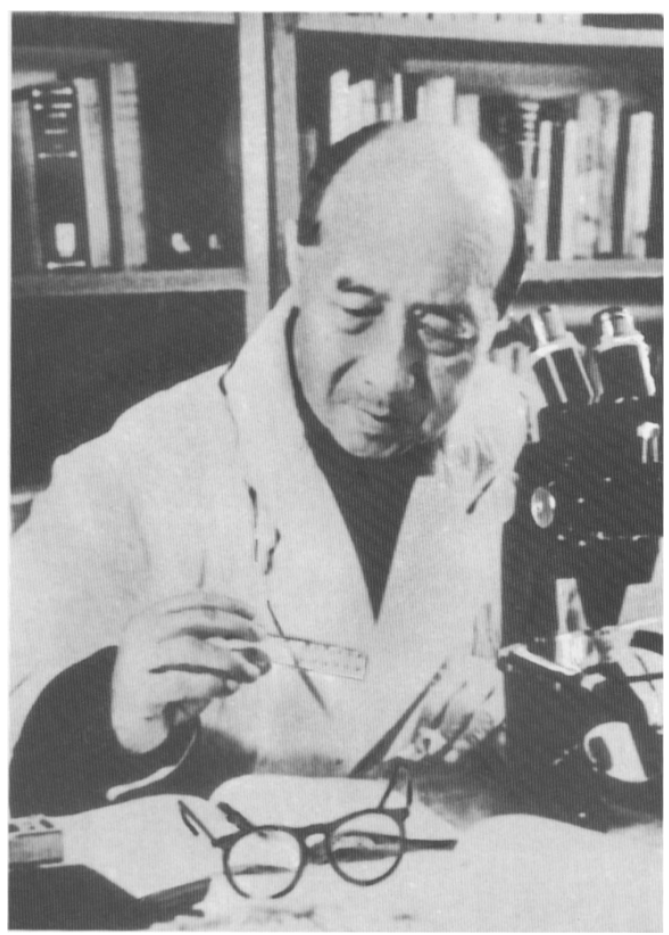

Figure 1. Prof. Chi Ping (1886-1965) (from Chi Ping Selection 《秉志文存》).

phibian and reptant animals, and mycologists Fon-Land Tai (戴芳澜) and S.C. Teng (邓叔群), who were respectively the first director and deputy director of the Institute of Microbiology of the CAS, all received their trainings at Cornell University. Among the Cornell alumni, there were also high-ranking government officials, such as T. H. Chien (钱天鹤), who was the vice minister of the Ministry of Agriculture and Forestry of the Nationalist government from 1940-1947, and Xiandong Yang (杨显东), who was appointed the vice minister of the Ministry of Agriculture after the establishment of the People's Republic of China. 


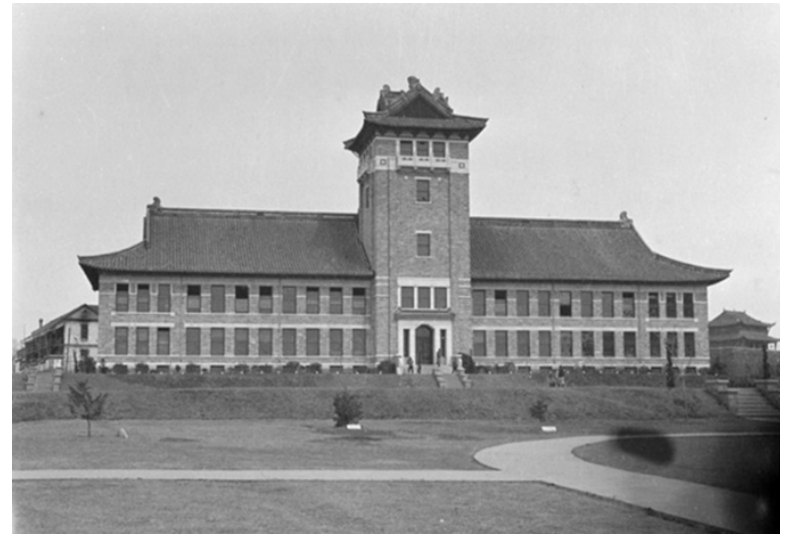

Figure 2. The north building of Nanking University, built in 1919.

Besides the zoologists and mycologists, Cornell University also trained the first plant geneticists of China, including Zonghan Shen (沈宗瀚), Shanbao Jin (金善宝), Hsien-Wen Li (李先闻), C. H. Li (李竞雄) and Che-Fang Feng (冯泽芳). They were all plant geneticists toward agricultural application of food and industrial plants. For example, Zonghan Shen and Shanbao Jin were specialized in wheat breading, and Che-Fang Feng was an expert in cotton breeding. In the 1930s and 1940s, even more students were sent to Cornell to study agricultural science, most of whom were from the Nanking University (Fig. 2).

Nanking University, founded in 1910, was an American missionary school that developed a close bond with Cornell University through a program called 'Plant Improvement and Genetics' Program during 1925-1930. According to the program, senior Cornell faculty from the Plant Breeding Department came to China working as teachers, organizers, advisors and researchers at the Nanking University. Mean-

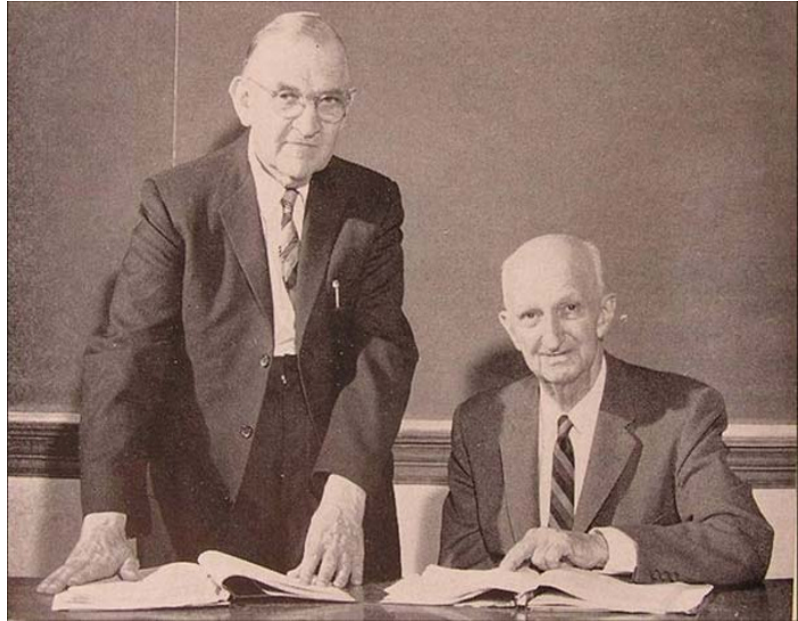

Figure 3. Prof. Harry H. Love (right).

while, Chinese students were also sent to Cornell. By 1946 over 60 students were sent to study at the Plant Breeding Department of Cornell University. Among the Cornell faculty was Prof. Harry H. Love (Fig. 3), who not only worked at Nanking University, but served as an advisor on agriculture and crop improvement for the Ministry of Industry of the Nationalist government. Prof. Love was also the first chief technician of the Central Laboratory of Agriculture in China, a government sponsored research institute. Later on, he published a book based on his experience in China: The Cornell-Nanking Story; The First International Technical Cooperation Program in Agriculture by Cornell University.

It is unarguable to say that the contribution to modern biology in China from Cornell University was substantial. It not only trained the core group of scientists and educators, but also positively affected the general agricultural application in China, despite the turbulent times of war. 